\title{
山东曲阜地区蚂蚁群落结构及物种多样性研究
}

\author{
刘 红 袁兴中 \\ (重庆大学资源及环境科学学院, 重庆 400044) \\ 张承德 \\ (曲阜师范大学生物系, 山东曲阜 273165 )
}

摘要: 通过诱捕法和样方调查法获得曲阜地区蚂蚁 4 亚科 15 属 19 种。优势种为菱结大头蚁 (Pheidole rhombino$d a$ )、粗面收获蚁 (Messor aciculatus) 和异色草蚁 (Lasius alienus) ,前 2 种亦是研究区域的广布种。根据调查数据分 析了该地区 5 种生境中蚂蚁群落的结构及多样性特征, 以及人为干扰和生境异质性对蚂蚁群落的影响。结果表 明 5 种生境中蚂蚁群落种类组成和多样性等指标均不相同。落叶阔叶林中蚂蚁群落种类数、Shannon-Wiener 多样 性指数 $\left(H^{\prime}\right)$ 和 Pielou 均匀度指数 $(J)$ 最高; 人工杨树林中蚂蚁群落 Shannon-Wiener 多样性指数 $\left(H^{\prime}\right)$ 最低; 河滩草丛 中蚂蚁巢数、个体数以及种类优势度指数 $(D)$ 最高。人类干扰越强的生境, 蚂蚁群落多样性指数越低; 生境质量和 异质性越高的生境, 蚂蚁群落多样性指数越高。聚类分析与群落结构序列分析结果基本一致, 人工杨树林与人居 环境中蚂蚁群落相似性最高, 其他几个生境蚂蚁群落间相似性很低。同种蚂蚁在不同生境中巢穴和蚁群大小有差 异。

关键词: 蚂蚁, 群落结构, 物种多样性, 生境, 曲阜

中图分类号:Q968.1 文献标识码: A 文章编号 : 1005-0094(2002)03-0298-07

\section{Community structure and species diversity of ant in Qufu, Shandong Province}

LIU Hong , YUAN Xing-Zhong

College of Resources and Environmental Science, Chongqing University, Chongqing 400044

ZHANG Cheng-De

Department of Biology , Qufu Normal University , Qufu 273165

Abstract : Ant specimens of 4 subfamilies , 15 genera and 19 species were collected by trap and sample plot methods in Qufu area, Shandong. The dominant species are Pheidole rhombinoda, Messor aciculatus and Lasius alienus, of which the first two species are widely distributed over the study area. Based on these samples, species composition, species diversity, and similarity of ant communities in five habitats were analyzed, and the extent of influence by human activity and habitat heterogeneity were examined. We find that species composition and diversity indices of ant communities are different in each of the five habitats. The number of species, Shannon-Wiener's diversity index $\left(H^{\prime}\right)$ and Pielou's evenness index $(J)$ in deciduous broad-leaved forest are the highest, while the diversity index in artificial poplar plantations is the lowest. The number of nests, number of individuals and McNaughton's dominant index $(D)$ is the highest in grasslands of river floodplains. The more the habitats are disturbed, the lower the diversity index of ant community is. The highest diversity indices were observed in the habitats with high quality and high heterogeneity. Clustering analysis for five ant communities and ordination analysis for community structure by multidimensional scaling (MDS) were carried out and basiccally identical results were obtained. The results show that similarity of ant communities between artificial poplar plantation and residential districts is the highest, and similarities between other habitats are much lower. Nest size and individual number of colonys of the same ant species are different in different habitats. 
Key words : ants , community structure, species diversity, habitat, Qufu

\section{1 引言}

蚂蚁是昆虫纲 Insecta，膜翅目 Hymenoptera，蚁 科 Formicidae 昆虫的总称, 是地球上分布最广泛、数 量最多的社会性昆虫。作为陆地生态系统的重要类 群, 蚂蚁能改良土壤、分解有机质、为植物传播种子、 传授花粉、保护植物抵御其他昆虫的危害、捕食农林 害虫，等等。因此，作为自然生态系统中食物链的重 要环节, 蚂蚁在成土作用、营养物质循环、植物生长 更新及维持生态平衡方面起着重要的作用 ( Holldobler \& Wilson, 1990)。由于蚂蚁的丰度和生态多 样性较高，以及具有高生物量、群落动态易被观测和 在整个营养水平上的生态重要性，因而成为生态监 测中很有吸引力的生物指标 (Majer \& Kock, 1992 ; Andersen , 1990 ; Andersen，1995)。因为蚂蚁对环 境变化敏感,故在生物多样性对环境变化反应的研 究中, 常常被作为关键类群进行研究 (Perfecto \& Snelling , 1995 ; Bestelmeyer \& Wiens , 1996 ; Catangui , 1996)。因为蚂蚁群落在生态系统的恢复过程 中始终显示出很明显的演替格局 (Majer，1992； Andersen，1993)，在澳大利亚和巴西等国家，蚂蚁 群落已被采矿业广泛用来作为采矿废弃地生态恢复 的指标。最近, 国外学者正在致力于蚂蚁功能群的 研究, 并与环境扰动和胁迫联系在一起, 以了解和预 测蚂蚁群落对土地利用的反应 (King et al. , 1998 ; Vanderwoude et al. , 1997 ; Bestelmeyer \& Wiens, 1996 )。

我国蚂蚁资源丰富，已调查的种类有 7 亚科 600 种以上 (唐觉等,1995)。近年来,有关蚂蚁生态 研究方面的报道多见于热带地区和东北地区(张智 英等 2000 ;徐正会等,1999;刘红,袁兴中,1996; 刘 红等, 1997)。作为暖温带典型地带的山东省曲阜 地区蚂蚁种类调查、生态研究迄今未见报道。作者 于 1996 年 5 10 月, 对曲阜地区蚂蚁进行了调查研 究, 本文总结并探讨了曲阜地区主要生境中蚂蚁群 落种类组成、多样性特征、群落结构与环境的相关 性, 旨在为我国暖温带地区蚂蚁资源及生态系统保 护提供科学依据。

\section{2 研究区域自然概况}

曲阜地处鲁中南山地丘陵的西南边缘, 地理位
置在 $35^{\circ} 29^{\prime} \sim 35^{\circ} 49^{\prime} \mathrm{N}$ 和 $116^{\circ} 51^{\prime} \sim 117^{\circ} 13^{\prime} \mathrm{E}$ 之间。 境内北、东、南三面多为山丘, 最高山峰海拔 $460 \mathrm{~m}$, 相对高差 $250 \mathrm{~m}$ 左右。中、西部则为平原, 山丘与平 原面积之比约为 3:7。泗河、沂河自东向西横贯全 境, 在曲阜境内分别被称为北沙河和南沙河。前者 在孔林以北, 后者位于城区以南, 距孔庙南门约 1 $\mathrm{km}$ 左右。近年来, 由于上游多处蓄水截流, 北沙河、 南沙河在枯水期几乎断流, 夏季丰水期河面宽不超 过 $20 \mathrm{~m}$ 。本地气候属暖温带季风大陆性气候, 四季 分明, 光热资源丰富, 降水较为充足。年均气温 $13.6^{\circ} \mathrm{C}$,年均降水量 $691.4 \mathrm{~mm}$,多集中于 $6 \sim 8$ 月, 大气相对湿度为 $68 \%$ 。地带性植被为暖温带落叶 阔叶林, 地带性土壤为棕壤和褐土。

\section{3 研究方法}

\section{1 样地设置}

在研究区域共选择 5 种生境作为研究样地 (表 1)。

\section{2 样方调查和诱集法}

采用样方调查和诱集法, 于 1996 年 5 10 月进 行蚂蚁群落的定量和定性调查。在每个样地内随机 选取 4 个 $5 \mathrm{~m} \times 5 \mathrm{~m}$ 的样方, 在地面划定样方范围 后, 仔细检查地表层蚂蚁个体和蚁巢。捕捉全部零 散个体保存于盛有 $75 \%$ 乙醇的小瓶内。发现蚁巢 时, 用小铁锹挖掘土壤层, 深度 $20 \mathrm{~cm}$, 仔细检查蚁 巢及个体, 然后将整个蚁巢铲入白色瓷盘 $(20 \mathrm{~cm} \times$ $30 \mathrm{~cm})$ 内, 又将该瓷盘放于 $40 \mathrm{~cm} \times 50 \mathrm{~cm}$ 的大瓷盘 中, 大瓷盘中放有水, 以防蚂蚁逃散。再将土块敲碎 搅匀, 收集各巢中蚂蚁, 并将蚂蚁标本放入盛有乙醇 的小瓶。收集蚂蚁的诱集法是在每个生境中随机埋 放 50 个塑料杯 (直径约 $7 \mathrm{~cm}$, 深约 $10 \mathrm{~cm}$ ) , 杯埋在 土中, 只剩上部边缘露出土壤表面, 杯内盛有 $1 / 2$ 容 量的 $3 \%$ 乙醛溶液。48 小时后取出塑料杯, 将杯中 蚂蚁收集到盛有乙醇的标本瓶内。居民区因人为活 动频繁, 不宜进行诱集。样方调查法的优点是能定 量采集和统计分析,而诱集法主要是一种定性采集 方法, 能弥补样方调查法所遗漏的种类, 两种方法的 结合能保证调查期间获得该区域较全面的蚂蚁群落 种类组成情况。统计分析主要以样方调查的数据进 行。以传统形态分类学方法对蚂蚁标本逐一分类鉴 
表 1 研究区域生境概况

Table 1 Habitat conditions of study area

\begin{tabular}{|c|c|c|c|c|c|}
\hline & Habitat I & Habitat II & Habitat III & Habitat IV & Habitat V \\
\hline $\begin{array}{l}\text { 所处位置 } \\
\text { Location }\end{array}$ & $\begin{array}{l}\text { 曲阜城北 } 25 \mathrm{~km} \text { 石 } \\
\text { 门山国家森林公园 } \\
\text { 内 } \\
\text { Located in Shimen- } \\
\text { shan National Forest } \\
\text { Park, } 25 \mathrm{~km} \text { apart } \\
\text { from Qufu City }\end{array}$ & $\begin{array}{l}\text { 曲阜城北 } 1.5 \mathrm{~km} \text { 的 } \\
\text { 孔林内 } \\
\text { Located in Confucian } \\
\text { graveyard of the } \\
\text { northern part of Qufu }\end{array}$ & $\begin{array}{l}\text { 南沙河阶地 } \\
\text { Alluvial terrace of } \\
\text { Nansha River }\end{array}$ & $\begin{array}{l}\text { 北沙河开阔河滩 } \\
\text { Beisha River beach }\end{array}$ & $\begin{array}{l}\text { 城内居民区 } \\
\begin{array}{l}\text { Residential area in } \\
\text { city }\end{array}\end{array}$ \\
\hline $\begin{array}{l}\text { 植被状况 } \\
\text { Vegetation condition }\end{array}$ & $\begin{array}{l}\text { 落叶乔、灌木 } 60 \text { 余 } \\
\text { 种, 盖度为 } 60 \% \text { 作草本植物 } \\
70 \% \text {,林下富 } \\
\text { About } 60 \text { deciduous } \\
\text { tree and shrub species } \\
\text { with coverage } 60 \% \text { } \\
70 \% \text {, rich in herbs } \\
\text { under forest }\end{array}$ & $\begin{array}{l}\text { 乔灌木约 } 20 \text { 余种, } \\
\text { 盖度为 } 60 \% \text {,林下草 } \\
\text { 本植物植物稀少 } \\
\text { About } 20 \text { tree and } \\
\text { shrub species with } \\
\text { coverage } 60 \% \text {, few } \\
\text { herbs under forest }\end{array}$ & $\begin{array}{l}\text { 林下空旷,几乎无灌 } \\
\text { 木生长, 草本盖度为 } \\
80 \% \\
\text { Almost no shrub, } \\
\text { grass community cov- } \\
\text { erage } 80 \%\end{array}$ & $\begin{array}{l}\text { 无乔灌木, 只有多种 } \\
\text { 草本植物生长 } \\
\text { No trees or shrubs, } \\
\text { only herbs }\end{array}$ & $\begin{array}{l}\text { 植物种类稀少 } \\
\text { Few plant species }\end{array}$ \\
\hline $\begin{array}{l}\text { 土壤状况 } \\
\text { Soil condition }\end{array}$ & $\begin{array}{l}\text { 棕色森林土, 枯枝落 } \\
\text { 叶层疏松, 厚约 } 3 \sim 5 \\
\mathrm{~cm} \\
\text { Brown forest soil, } \\
\text { loose forest litter of } \\
\text { about } 3 \sim 5 \mathrm{~cm} \text { deep }\end{array}$ & $\begin{array}{l}\text { 潮褐土 } \\
\text { Calcareous soil }\end{array}$ & $\begin{array}{l}\text { 棕壤, 土壤板结坚硬 } \\
\text { Brown soil , and hard- } \\
\text { en }\end{array}$ & $\begin{array}{l}\text { 沙质土,上干下潮, } \\
\text { 下层粘重 Sand soil, } \\
\text { dry on the top and } \\
\text { damp below, sticky } \\
\text { in below }\end{array}$ & $\begin{array}{l}\text { 棕壤, 零星分布 } \\
\text { Brown soil , scattered } \\
\text { distribution }\end{array}$ \\
\hline $\begin{array}{l}\text { 人为干扰 } \\
\text { Disturbance }\end{array}$ & $\begin{array}{l}\text { 较少 } \\
\text { Slight }\end{array}$ & $\begin{array}{l}\text { 较少 } \\
\text { Slight }\end{array}$ & $\begin{array}{l}\text { 很强 } \\
\text { Very intense }\end{array}$ & $\begin{array}{l}\text { 较少 } \\
\text { Slight }\end{array}$ & $\begin{array}{l}\text { 强 } \\
\text { Intense }\end{array}$ \\
\hline
\end{tabular}

生境 I : 落叶阔叶林; 生境 II : 针阔混交林; 生境 III : 人工杨树林; 生境 IV : 河滩草丛; 生境 V : 人居环境

Habitat I : Deciduous broad-leaf forest ; Habitat II : Mixed conifer and broad-leaved forest ; Habitat III : Artificial poplar forest ; Habitat IV : River beach grassland ; Habitat $\mathrm{V}$ : Residential area

定（Bingham，1903；Bolton，1994；吴坚,王常禄， $1995 ;$ 唐觉等,1995) ,部分标本委托浙江大学植物 保护系李参教授鉴定。

\section{3 计算公式}

本研究根据蚂蚁群落的特点及取样数据, 选择 使用了以下计算公式 (Pielou，1975; 马克平 ,1994) 进行数据及结果的分析。

1) Margalef 种类丰度: $S_{1}=S-1 / \log _{2} N$;

2) Shannon-Wiener 指数: $H^{\prime}=-\sum P_{i} \log _{2} P_{i}$;

3 ) Pielou 的均匀度指数 :

$$
J=\left(-\sum P_{i} \log _{2} P_{i}\right) / \log _{2} S
$$

4 ) McNaughton 种类优势度指数 :

$$
D=\left(N_{1}+N_{2}\right) / N
$$

$5)$ Sorenson 相似性系数: $\mathrm{S}_{2}=2 C /(A+B)$

式中,$S$ 为总种数, $P_{i}$ 为种 $i$ 的个体数占总个体数的 比例,$N$ 为所有种的个体总数, $N_{1} 、 N_{2}$ 为样品中居第 一、二位的优势种的个体数, $A$ 为 $\mathrm{A}$ 生境中的种类 数, $B$ 为 $\mathrm{B}$ 生境中的种类数, $C$ 为 $\mathrm{A} 、 \mathrm{~B}$ 两生境共有 的种类数。利用 STATISTICA 统计软件 (StatSoft Inc. , USA，1993），以 Sorenson 相似性系数为基础, 进行群落聚类分析和多维序列分析 (Multidimentional Scale, MDS)。

\section{4 结果与分析}

\section{1 种类组成}

鉴定诱集和样方调查所得标本,共有蚂蚁 19 种，隶属于 4 亚科 15 属 (表 2 )。5 种生境共发现蚁 巢 617 个,统计蚂蚁个体总数 361246 只。就个体 数而言 5 种生境蚂蚁优势种 (个体数 /总个体数 > $10 \%$ 的种类) 为菱结大头蚁 (Pheidole rhombinoda)、 粗面收获蚁 (Messor aciculatus) 和异色草蚁 (Lasius alienus)。从生境分布来看, 仅菱结大头蚁和粗面收 获蚁分别出现于 4 种生境, 异色草蚁只出现于 2 种 生境中。综合个体数量及分布范围等指标, 作者认 为菱结大头蚁和粗面收获蚁是研究区域的广布种。 常见种 $(1 \%<$ 个体数/总个体数 $<10 \%)$ 有 8 种, 其 中 6 种分别生活于 3 种生境; 稀有种 (个体数/总个 体数 $<1 \%) 8$ 种, 其中 7 种分别只生活在 1 种生境 中。

从表 1 可知, 各生境蚂蚁群落种类组成和数量 均有差异。落叶阔叶林蚂蚁种类最丰富, 优势种为 菱结大头蚁、杰氏斜结蚁 (Plagiolepis jerdoni) 和日本 弓背蚁 (Camponotus japonicus)，它们的个体数分别 占该生境蚂蚁总数的 $28.55 \% 、 26.65 \%$ 和 $15.41 \%$, 
表 2 研究区域蚂蚁群落种类组成及数量 (单位 : 只)

Table 2 The species composition and quantity of ant community in the study area

\begin{tabular}{|c|c|c|c|c|c|c|c|c|}
\hline $\begin{array}{l}\text { 种名 } \\
\text { Species }\end{array}$ & $\begin{array}{c}\text { 生境 I } \\
\text { Habitat I }\end{array}$ & $\begin{array}{c}\text { 生境 II } \\
\text { Habitat II }\end{array}$ & $\begin{array}{c}\text { 生境 III } \\
\text { Habitat III }\end{array}$ & $\begin{array}{c}\text { 生境 IV } \\
\text { Habitat IV }\end{array}$ & $\begin{array}{c}\text { 生境 V } \\
\text { Habitat V }\end{array}$ & $\begin{array}{l}\text { 合计 } \\
\text { Total }\end{array}$ & $\begin{array}{c}\text { 占总个体数 } \\
\text { 百分比 } \%\end{array}$ & $\begin{array}{c}\text { 多度 } \\
\text { Dominant }\end{array}$ \\
\hline 耶氏狂蚁 Paratrechina yerburyi & 1837 & 2790 & & 1600 & & 6227 & 1.72 & ++ \\
\hline 异色草蚁 Lasius alienus & & 5800 & & 92480 & & 98280 & 27. 20 & +++ \\
\hline 黑腹平结蚁 Prenolepis melanogaster & & & & 2421 & & 2421 & 0.67 & + \\
\hline 纳氏平结蚁 $P r$. naorojii & & 1540 & 1460 & & 1270 & 4270 & 1.18 & ++ \\
\hline 杰氏斜结蚁 Plagiolepis jerdoni & 16200 & & & 3710 & & 19910 & 5.51 & ++ \\
\hline 丝光褐林蚁 Formica fusca & 1000 & & 750 & 2400 & & 4150 & 1.15 & ++ \\
\hline 日本弓背蚁 Camponotus japonicus & 9370 & 19800 & 3690 & & & 32860 & 9. 10 & ++ \\
\hline 铺道蚁 Tetramorium caespitum & 2400 & & 7840 & & 10330 & 20570 & 5.69 & ++ \\
\hline 铺道蚁属一种 Tetramorium sp. & 673 & & & & & 673 & 0.19 & + \\
\hline 花居小家蚁 Monomorium floricola & 2300 & 3870 & & & & 6170 & 1.71 & ++ \\
\hline 中华小黑家蚁 M. chinensis & 815 & & & 1248 & & 2063 & 0.57 & + \\
\hline 粗面收获蚁 Messor aciculatus & 4350 & & 35200 & 5280 & 9480 & 54310 & 15.03 & +++ \\
\hline 塞奇举腹蚁 Crematogaster sagei & 1613 & & & & & 1613 & 0.45 & + \\
\hline 比罗举腹蚁 $C$. biroi & & 2540 & & & & 2540 & 0.70 & + \\
\hline 菱结大头蚁 Pheidole rhombinoda & 17360 & 13000 & & 67500 & 1060 & 98920 & 27.38 & +++ \\
\hline 中国短猛蚁 Brachyponera chinensis & 2120 & 1450 & & & 372 & 3942 & 1.09 & ++ \\
\hline 费氏中盲猛蚁 Centromyrmex feae & & 849 & & & & 849 & 0.24 & + \\
\hline 格氏姬猛蚁 Hypoponera gleadowi & 758 & & & & & 758 & 0.21 & + \\
\hline 狡臭蚁 Technomyrmex elatior & & 720 & & & & 720 & 0.2 & + \\
\hline 个体总数 Total number of individuals & 60796 & 52359 & 48940 & 176639 & 22512 & 361246 & 100.00 & \\
\hline 物种数 No. of species & 13 & 10 & 5 & 8 & 5 & 19 & & \\
\hline 巢数 No. of nests & 60 & 64 & 67 & 398 & 28 & 617 & & \\
\hline
\end{tabular}

+++ : individual number $>10 \% ;++$ : individual number is between $1 \%$ and $10 \% ;+:$ individual number $<1 \%$

铺道蚁属一种 (Tetramorium sp.) 、塞奇举腹蚁 (Crematogaster sagei) 和格氏姬猛蚁 (Hypoponera gleadowi ) 仅生活于该生境中。菱结大头蚁和日本弓背蚁 同时又是针阔混交林的优势种,分别占针阔混交林 生境中蚂蚁总数的 $24.83 \%$ 和 $37.82 \%$,该生境另一 优势种为异色草蚁,占 $11.08 \%$,比罗举腹蚁 (Crematogaster biroi)、费氏中盲猛蚁 (Centromyrmex feae) 和隆背狡臭蚁 (Technomyrmex modiglianii elatior) 仅 出现于该生境中。人工杨树林和人居环境中蚂蚁种 类最少, 而且优势种都是粗面收获蚁和铺道蚁 ( Tetramorium caespitum) ,但粗面收获蚁在人工杨树林中 占绝对优势，个体数占该生境总数的 $71.92 \%$ 。而 在人居环境中两种蚂蚁所占百分比近似, 分别为 $42.11 \%$ 和 $45.89 \%$,人居环境中蚁巢数和个体数最 少。河滩草丛中以异色草蚁和菱结大头蚁为优势 种，耶氏狂蚁 (Paratrechina yerburyi) 和中华小家蚁 (Monomorium chinensis) 为稀有种, 黑腹平结蚁 (Prenolepis melanogaster) 仅生活在该生境内，该生境蚂 蚁巢数和个体数最高。

\section{2 多样性特征}

5 种生境蚂蚁群落多样性指标列于表 3 。从表
3 可知, 落叶阔叶林中蚂蚁种类优势度最低,而种类 丰度、多样性指数和均匀度指数均位居第一。针阔 混交林内蚂蚁群落的种类丰度、多样性指数和均匀 度指数仅次于落叶阔叶林, 优势度略高于落叶阔叶 林。人工杨树林蚂蚁群落种类丰度和多样性指数最 低。而均匀度最低、优势度最高的则是河滩草丛的 蚂蚁群落, 这说明该生境蚂蚁个体数在种间分布最 不均匀, 但该生境蚂蚁种类丰度却高于人工杨树林 和人居环境。5 种生境蚂蚁群落多样性指数是落叶 阔叶林 $>$ 针阔混交林 $>$ 人居环境 $>$ 河滩草丛 $>$ 人工 杨树林。由于多样性指数包含种类数和种类分布均 匀性 2 种成分, 在河滩草丛中虽然蚂蚁种类丰度高 于人居环境, 但均匀度却低于后者, 结果多样性指数 低于后者,在此应是高的均匀性起了关键作用。同 样情况, 河滩草丛蚂蚁种类丰度高于人工杨树林, 均 匀度也低于后者, 结果多样性指数却是前者高于后 者, 这里应该是高的种类丰度发挥了关键作用。因 此, 当种类丰度和均匀性变化一致时, 多样性指数与 二者成正相关;当二者变化不一致时，多样性指数取 决于二者的相对大小。 
表 35 种生境蚂蚁群落多样性指标

Table 3 The diversity indexes of ant community in five habitats

\begin{tabular}{ccccc}
\hline $\begin{array}{c}\text { 生境 } \\
\text { Habitat }\end{array}$ & $\begin{array}{c}\text { Margalef 种类丰度 } \\
\text { Margalef richness index }\end{array}$ & $\begin{array}{c}\text { Shannon-Weiner 指数 } \\
\text { Shannon-Weiner index }\end{array}$ & $\begin{array}{c}\text { Pielou 均匀度 } \\
\text { Pielou equality index }\end{array}$ & $\begin{array}{c}\text { McNaughton 优势度 } \\
\text { McNaughton dominance }\end{array}$ \\
\hline I & 1.09 & 1.99 & 0.78 & 0.55 \\
II & 0.83 & 1.78 & 0.77 & 0.63 \\
III & 0.37 & 0.89 & 0.56 & 0.87 \\
IV & 0.58 & 1.09 & 0.52 & 0.91 \\
V & 0.40 & 1.10 & 0.68 & 0.88
\end{tabular}

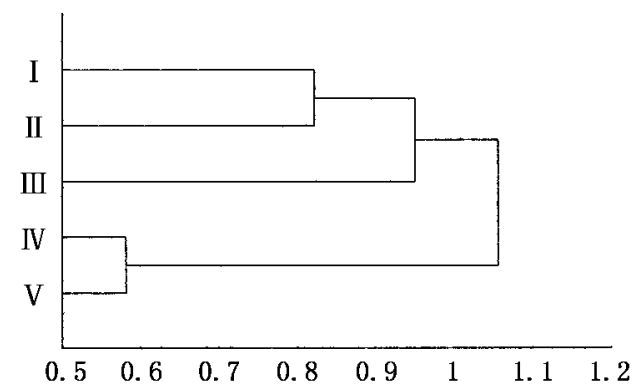

图 1 不同生境蚂蚁群落聚类树状图

Fig. 1 Dendrogram of cluster analysis on ant community in different habitats

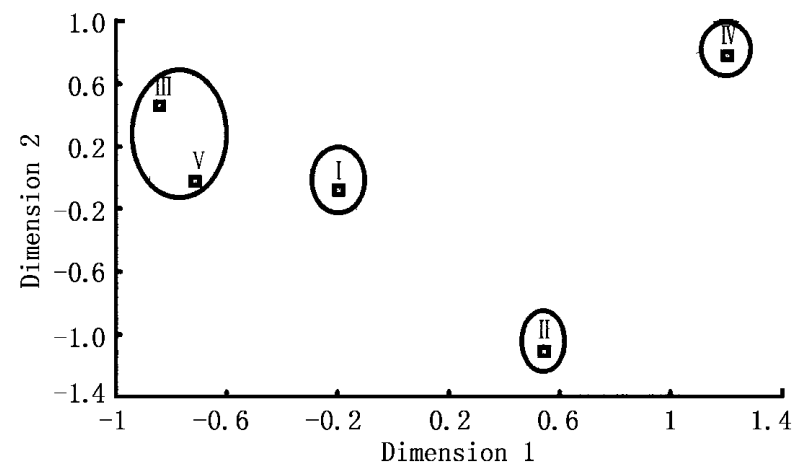

图 25 种生境中蚂蚁群落 MDS 分析图

Fig. 2 Multidimentional scaling ( MDS) ordination plot of ant community samples taken from five habitats

\section{3 群落结构分析}

为了揭示不同生境中蚂蚁群落的差异水平, 以 各生境中蚂蚁群落相似性系数为基础, 对研究区域 蚂蚁群落进行聚类分析和群落结构序列分析 (MDS) (图 1、图 2)。在图 1 中，根据欧氏距离坐标 (d) 可看出各生境聚合是在什么水平上进行的,聚 合水平越低的生境, 其蚂蚁群落越相似。图中显示 $d$ 值为 1.06 时, 研究区域蚂蚁群落被分为两大类： 第一类 (包括落叶阔叶林、针阔混交林和河滩草丛 的蚂蚁群落) 是受人类活动影响较小、自然生境质 量较好的蚂蚁群落;第二类是生境受人类活动强烈
干扰的蚂蚁群落，包括人工杨树林和人居环境 2 种 生境的蚂蚁群落。这一水平的划分体现了人为干扰 对蚂蚁群落结构的影响。当 $d$ 值降低为 0.95 时, 第 一类蚂蚁群落又分为以乔灌木植物为主的森林景观 蚂蚁群落和以草本植物为主的开阔景观蚂蚁群落 2 类, 体现了植被类型及结构对蚂蚁群落的影响。森 林景观包括落叶阔叶林和针阔阔叶林。图中最小 $d$ 值为 0.58 ,此处人工杨树林和居民区最先聚合在一 起, 说明这 2 种生境蚂蚁群落相似程度最高。

MDS 分析表明 5 种生境的蚂蚁群落被分成了 4 个不同的聚类组 (图 2)。MDS 连续展示了生境间 蚂蚁群落组成的相似关系, 因为群落组成越相似, 代 表它们的点在 MDS 图上的距离就越近; 反之, 群落 组成相差越远, 代表它们的点在图上的距离也越远。 从图 2 可以看出, 距离最近的两点是人工杨树林和 人居环境, 它们聚合为一个组, 说明它们的相似性最 大, 而它们与落叶阔叶林、针阔混交林、河滩草丛之 间的距离则相对较大, 尤其是河滩草丛远离其他几 个生境, 说明它们之间的相似性极小。比较图 1 和 图 2 ,可看出两种分析的结果基本一致, 虽然在图 1 中落叶阔叶林和针调混交林聚合在一起, 但它们聚 合处的 $d$ 值较高, 而且在图 2 中，二者的代表点相距 也较远。因此 5 种生境中, 除人工杨树林和人居环 境的蚂蚁群落相似性较高外, 其他几个生境蚂蚁群 落的相似性均很小。

\section{5 讨论}

1) 本研究区域共获蚂蚁 19 种,隶属于 4 亚科 15 属。与我国热带的西双版纳地区和东北吉林省 相比（张智英等,2000;徐正会等,1999;刘红等， 1997 ), 本研究区域蚂蚁种类比前者贫乏而较后者 丰富。这说明蚂蚁种类数量和多样性随纬度增加而 降低, 其变化规律与我国东部生物群落的纬度地带 性规律一致。 
2) 多样性分析表明 ,5种生境中蚂蚁群落种类 丰度为落叶阔叶林 $>$ 针阔混交林 $>$ 河滩草丛 $>$ 人居 环境 $>$ 人工杨树林, 多样性指数是落叶阔叶林 $>$ 针 阔混交林 >人居环境 > 河滩草丛 >人工杨树林, 这 与各生境质量优劣有关。落叶阔叶林是分布在石门 山国家森林公园的次生落叶阔叶林, 受人为干扰较 少; 针阔混交林分布于孔林内,由于保护较好,林内 植物生长良好。由于落叶阔叶林、针阔混交林环境 条件较好, 故蚂蚁种类丰度和多样性较高, 且两种生 境拥有其他生境所没有的 3 个特有种 (落叶阔叶林 特有种是铺道蚁属一种 (Tetramorium sp.)、塞奇举 腹蚁 (Crematogaster sagei) 和格氏姬猛蚁 (Hypoponera gleadowi); 针阔混交林特有种是比罗举腹蚁 (Crematogaster biroi)，费氏中盲猛蚁（Centromyrmex feae) 和隆背狡臭蚁( Technomyrmex modiglianii elatior )。人工杨树林紧靠南沙河, 南沙河附近一些小工 厂 (如造纸厂等) 常年将未经任何处理的废水排入 河内, 使河水污浊不堪, 污水在阳光照射下, 一些有 毒的气体挥发出来, 直接危害杨树林内生物的生长。 加之该生境距居民区不远，常有人、畜活动，因此，林 下植物稀少, 土壤板结坚硬，限制了蚂蚁的筑巢和活 动。河滩草丛位于北沙河河滩，距居民区较远，平时 有少数村民放羊于此,羊的啃食和践踏给草本植物 生长带来一定影响。人居环境为居民区，土壤零星 分布, 能为蚂蚁提供的生活空间和食物资源较少, 蚂 蚁只能筑巢于路边、房屋附近和零星分布的土壤中。 5 种生境蚂蚁群落种类丰度和多样性格局揭示了人 类活动对 5 种生境干扰的强度, 因此, 蚂蚁群落结构 及多样性特征可以作为指示环境变化和生境质量的 指标。

3 ) 在自然因素和人为因素的共同作用下，环境 产生分异, 生物适应环境的同时便形成了相应的群 落。人工杨树林和人居环境的蚂蚁群落相似性最 高, 主要是因两种生境受人为干扰较严重, 生境质量 差, 只有少数耐受力强的蚂蚁种类能生活在这种生 境中，从而使这两种生境蚂蚁群落的种类少, 且组成 相似。落叶阔叶林、针阔混交林、河滩草丛蚂蚁群落 之间相似性极小的原因，主要是各生境的自然条件， 尤其是植物条件和土壤条件不同所致。落叶阔叶林 和针阔混交林均为森林, 但前者植物种类比后者更 丰富, 且均为落叶植物, 又因坡度引起小地形差异, 使生境内异质性高，小生境多样，故落叶阔叶林中蚂
蚁种类数最高。而针阔混交林中有许多人工种植的 侧柏树, 针叶植物的生长和其残落物对生境内小气 候、土壤的发育等影响不同于落叶植物。河滩草丛 为开阔的草地, 植物群落类型和土壤条件明显不同 于落叶阔叶林和针阔混交林。因此, 蚂蚁群落的相 似性关系反映了生境间的相似程度。

不同生境条件还影响同种蚂蚁巢穴和蚁群大 小。以广布种菱结大头蚁为例, 在落叶阔叶林中, 植 物种类丰富, 土壤为棕色森林土, 土层厚, 结构好, 水、气比例适宜, 菱结大头蚁巢穴深而大, 每巢蚁群 个体数平均为 2170 只; 在河滩草丛中,植物种类少， 但盖度大, 土壤为沙质土, 上沙下粘, 地下水位高, 该 蚂蚁巢穴浅而小, 每巢蚁群个体数平均为 482 只。 同时, 又由于落叶阔叶林中蚂蚁种类丰富, 物种间对 空间和食物资源等的竞争，每个种所占有空间较小， 所以该生境中蚂蚁总巢数和每种蚂蚁的巢数都较 少。而开阔的草地生境, 蚂蚁种类较少, 种间竞争减 小, 每种蚂蚁可以占据更多的空间和食物资源, 所 以, 河滩草丛中蚂蚁总巢数和每种蚂蚁巢数都远较 针阔混交林多。菱结大头蚁的巢穴在落叶阔叶林中 共有 8 个, 而在河滩草丛中共有 140 个, 但因两生境 巢穴和蚁群大小不同, 使该蚂蚁个体数量在两生境 中都很高,而成为两生境的优势种。

致谢: 衷心感谢浙江大学植物保护系李参教授帮助 鉴定部分蚂蚁标本; 感谢美国科罗拉多州立大学 Bestelmeyer B. T. 博士和澳大利亚热带生态系统研 究中心的 Andersen A. N. 博士提供了大量宝贵的研 究资料。

\section{参考文献}

刘红, 陈鹏, 袁兴中, 1997. 吉林省蚂蚁资源及其实用价值研 究. 自然资源学报, 12(3)：276 281

刘红, 袁兴中, 1996. 吉林省左家蚂蚁及生态分布. 昆虫知 识, 33(4): 226 227

马克平, 1994. 生物多样性的测度方法. 见: 钱迎倩, 马克平 (主编), 生物多样性研究的原理与方法. 北京: 中国科 学技术出版社, $141 \sim 165$

唐觉, 李参, 黄恩友, 张本悦, 陈益, . 1995. 中国经济昆虫 志 膜翅目蚁科(一). 北京: 科学出版社, $1 \sim 2$

吴坚, 王常禄, 1995. 中国蚂蚁. 北京: 中国林业出版社, 1 $\sim 214$

徐正会, 曾光, 柳太勇, 何云峰, 1999. 西双版纳地区不同 植被亚型蚁科昆虫群落研究. 动物学研究, 20(2)：118 $\sim 125$ 
张智英，曹敏，杨效东，邓晓保，余宇平，2000。西双版纳 片断季节性雨林蚂蚁物种多样性研究. 动物学研究, 21 (1) : $70 \sim 75$

Andersen A N, 1995. A classification of Australian ant communities, based on functional groups which parallel plant lifeforms in relation to stress and disturbance. Journal of Biogeography, 22: $15 \sim 29$

Andersen A N, 1993. Ants as indicators of restoration success at a uranium mine in tropical Australia. Restoration Ecology, 1: $56 \sim 167$

Andersen A N, 1990. The use of ant communities to evaluate change in Australian terrestrial ecosystems: a review and a recipe. Proceedings of the Ecological Society of Australia, 16: $347 \sim 357$

Bestelmeyer B T and J A Wiens, 1996. The effects of land use on the structure of ground-foraging ant communities in the Argentine Chaco. Ecological Applications, 6(4): 1225 1240

Bingham C T, 1903. The fauna of British India including Ceylon and Burma (Hymenoptera 2). Ants and Cuckoo-wasps. Taylor and Francis, London, $1 \sim 414$

Bolton B, 1994. Identification guide to the ant genera of the world. Harvard University Press, Cambridge, $1 \sim 222$

Catangui M A, 1996. Abundance, diversity, and spatial distribution of ants (Hymenoptera: Formicidae) on mixed-grass rangelands treated with diflubenzuron. Environmental Ento- mology, 25: $757 \sim 766$

Holldobler B and E O Wilson, 1990. The ants. The Belknap Press of Harvard University Press, Cambridge, $1 \sim 732$

King J R, A N Andersen and A D Cutter, 1998. Ants as bioindicators of habitat disturbance: validation of the functional group model for Australia's humid tropics. Biodiversity and Conservation, 7: $1627 \sim 1638$

Majer J D, 1992. Ant recolonisation of rehabilitated bauxite mines of Pocos de Caldas, Brasil. Journal of Tropical Ecology, 8: $97 \sim 108$

Majer J N and A E de Kock, 1992. Ant recolonization of sand mines near Richards Bay, South Africa: an evaluation of progress with rehabilitation. South African Journal of Science, 88: $31-36$

Perfecto I and R Snelling, 1995. Biodiversity and the transformation of a tropical agroecosystem: ants in coffee plantations. Ecological Applications, 5: $1084 \sim 1097$

Pielou E C, 1975. Ecological diversity. John Wiley, New York Vanderwoude C, A N Andersen and A A House, 1997. Ant communities as bio-indicators in relation to fire management of spotted gum (Eucalyptus maculata Hook) forests in South-east Queensland. Memoirs of the Museum of Victoria, 56(2) : $671 \sim 675$

(责任审稿人 :周红章；责任编辑：间文杰） 